\title{
Heat-treated Ni-Ti Rotary Instruments Influencing the Success of Endodontic Treatments
}

\author{
Rodolfo Reda ${ }^{1}$, Andrea Del Giudice ${ }^{2}$, Alessandro Mazzoni ${ }^{3}$, Shilpa Bhandi $^{4}$, Alessio Zanza ${ }^{5}$, Dario Di Nardo ${ }^{6}$ \\ World Journal of Dentistry (2020): 10.5005/jp-journals-10015-1782
}

Dental pulp could be compromised by mechanical, thermal, or chemical damages developed while performing restoration or by pathogenic bacteria that reach the pulpal tissues, ${ }^{1}$ penetrating from extensive primary decay, from a secondary decay that developed underneath a previous restoration, and for many other causes. When the health of dental pulp is compromised, and no longer recoverable, it is necessary to practice root canal therapy before proceeding with any kind of rehabilitation which could be conservative or prosthetic.

However, function, esthetic, and comfort can be achieved by eliminating or significantly reducing pathogenic bacteria, starting from a correct root canal instrumentation and irrigation, and preventing recontamination by a complete sealing of the canal system which could be guaranteed by effective isolation from oral cavity obtained by a congruous restauration. ${ }^{2}$

A significant contribution to the reduction of pathogenic bacteria from the main canals of a contaminated root canal system is performed by mechanical instrumentation. Instrumentation can be affected by the complexity of root canal anatomy and facilitated by the use of lubricants. ${ }^{3} \mathrm{Ni}$-Ti rotary instruments' separation is traditionally considered an uncommon event and it can happen often in cases of difficult anatomies: ${ }^{4}$ if stresses are excessive, they can lead to endodontic file separation. $\mathrm{Ni}$-Ti instruments can fail due to a mix of excessive torsional or flexural fatigue, with file fracture occurring principally in the apical third, where it is more difficult to understand the real anatomy and the canal is usually narrower or curved. ${ }^{4,5}$

Using cone-beam computed tomography (CBCT), it is possible to better evaluate the three-dimensional endodontic anatomy and to correctly visualize canal trajectories, due to select the most appropriate $\mathrm{Ni}$-Ti rotary instruments for a better approach of that case. ${ }^{6,7}$ During clinical practice, CBCT can help to visualize hidden curvatures, confluent or diverging canals, and bifurcations, which are very stressful conditions for the endodontic instrument. Unfortunately, CBCT on a routine basis is nowadays used only by a minority of clinicians due to increased costs and radiation risks. ${ }^{8}$

Since canal anatomy is complex and cannot be modified, the current best way to decrease the percentage of intracanal separation, besides using safer motions during instrumentation, is to use thermally treated or lower mass instruments, which can better resist flexural stresses. ${ }^{9,10}$

The most common studies available in the literature are in vitro evaluations and comparisons of mechanical properties of the $\mathrm{Ni}-\mathrm{Ti}$ instruments which investigate mainly the following properties: flexibility, cutting efficiency, cyclic fatigue, and torsional resistance. Heat treatments and the mass of the $\mathrm{Ni}$-Ti instruments were considered to be the most relevant in determining resistance to bending and torsional stress.
1-3,5,6 Department of Oral and Maxillo-Facial Sciences, Sapienza University of Rome, Rome, Italy

${ }^{4}$ Department of Restorative Dental Sciences, Jazan University, Jazan, Kingdom of Saudi Arabia

Corresponding Author: Alessio Zanza, Department of Oral and Maxillo-Facial Sciences, Sapienza University of Rome, Rome, Italy, Phone: +39 3348731467, e-mail: ale.zanza@gmail.com

How to cite this article: Reda R, Del Giudice A, Mazzoni A, et al. Heattreated Ni-Ti Rotary Instruments Influencing the Success of Endodontic Treatments. World J Dent 2020;11(6):437-438.

Source of support: Nil

Conflict of interest: None

Regarding heat treatment, a more martensitic file will be more resistant to flexural stress, but less resistant to torsional fatigue. ${ }^{11}$ Regarding the amount of mass, at the point of maximum stress, the lower is the mass, the higher flexural resistance will be shown. ${ }^{12}$

To conclude, heat-treated files allow to reach excellent clinical results, with lower intraoperative risks but longer operative times, due to the reduced cutting capacity. ${ }^{13}$ Despite this, they represent an important alternative for the treatment of cases with very difficult endodontic anatomies, minimizing the risk of iatrogenic errors and intracanal separation.

\section{References}

1. Neelakantan P, Romero M, Vera J, et al. Biofilms in endodonticscurrent status and future directions. Int J Mol Sci 2017;18(8):1748. DOI: 10.3390/ijms18081748.

2. Naoum HJ, Chandler NP. Temporization for endodontics. Int Endod J 2002;35(12):964-978. DOI: 10.1046/j.1365-2591.2002.00600.x.

3. Mazzoni A, Pacifici A, Zanza A, et al. Assessment of real-time operative torque during nickel-titanium instrumentation with different lubricants. Appl Sci 2020;10(18):6201. DOI: 10.3390/ app10186201.

4. Gambarini G, Miccoli G, D'Angelo M, et al. The relevance of operative torque and torsional resistance of nickel-titanium rotary instruments: a preliminary clinical investigation. Saudi Endod J 2020;10:260-264. DOI: 10.4103/sej.sej_157_19.

5. Alcalde MP, Duarte MAH, Bramante $C M$, et al. Cyclic fatigue and torsional strength of three different thermally treated reciprocating nickel-titanium instruments. Clin Oral Investig 2018;22(4):1865-1871. DOI: 10.1007/s00784-017-2295-8Erratum in: Clin Oral Investig. 2017 Dec 26.

6. Gambarini G, Piasecki L, Ropini P, et al. Cone-beam computed tomographic analysis on root and canal morphology of mandibular first permanent molar among multiracial population in Western European population. Eur J Dent 2018;12(3):434-438. DOI: 10.4103/ ejd.ejd_116_18. 
7. Gambarini G, Piasecki L, Miccoli G, et al. Cone-beam computed tomography in the assessment of periapical lesions in endodontically treated teeth. Eur J Dent 2018;12(1):136-143. DOI: 10.4103/ejd. ejd_320_17.

8. Patel S, Durack C, Abella F, et al. Cone beam computed tomography in endodontics - a review. Int Endod J 2015;48(1):3-15. DOI: 10.1111/ iej.12270.

9. Tabassum $\mathrm{S}$, Zafar K, Umer F. Nickel-titanium rotary file systems: what's new? Eur Endod J 2019;4(3):111-117. DOI: 10.14744/eej.2019.80664.

10. Gambarini G, Cicconetti A, Di Nardo D, et al. Influence of different heat treatments on torsional and cyclic fatigue resistance of nickeltitanium rotary files: a comparative study. Appl Sci 2020;10(16):5604. DOI: 10.3390/app10165604.
11. Seracchiani M, Miccoli $G$, Reda R, et al. A comprehensive in vitro comparison of mechanical properties of two rotary endodontic instruments. World J Dent 2020;11(3):185-188.DOI: 10.5005/jp-journals10015-1729.

12. Di Nardo D, Gambarini G, Seracchiani M, et al. Influence of different cross-section on cyclic fatigue resistance of two nickeltitanium rotary instruments with same heat treatment: an in vitro study. Saudi Endod J 2020;10:221-225. DOI: 10.4103/sej.sej_ 124_19.

13. Pedullà E, Leanza G, La Rosa GRM, et al. Cutting efficiency of conventional and heat-treated nickel-titanium rotary or reciprocating glide path instruments. Int Endod J 2020;53(3):376-384. DOI: 10.1111/ iej.13224. 